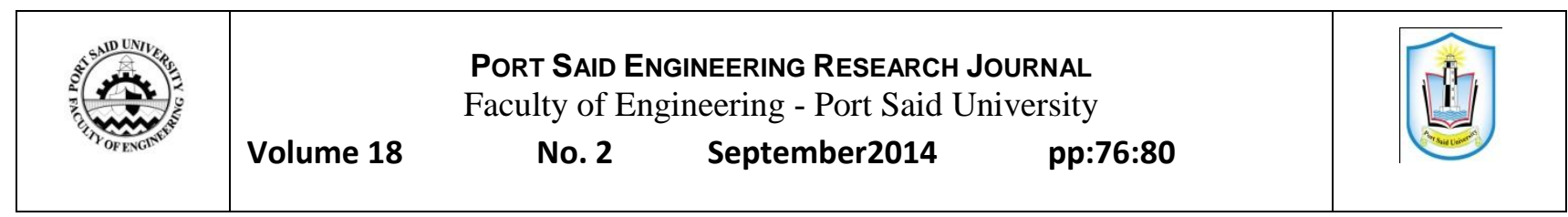

\title{
Analytical Solution Developed for Predicting Transient Interface in Coastal Confined Aquifers
}

\author{
Mohamed M. A. Somaida ${ }^{1}$ (Faculty of Engineering, Port Said University)
}

\begin{abstract}
:
For predicting the transient fresh-salt water interface in confined coastal aquifers, an equation has been developed to estimate the advance of interface. The equation depends on; the densities of fresh and salt water, the hydraulic properties of the aquifer and the rate of flow of groundwater in the fresh-water region. The developed equation is applied on a confined aquifer example to compute the average advance of interface. The estimated analytical value is found to have the same order of magnitude and nearly equal to the value estimated using the Ghyben-Herzberg relation, where the deviation is about 0.02. The agreement is considered satisfactory, since the developed equation considers the hydraulic properties and the actual hydrological conditions of the aquifer. However, the developed analytical solution seems to be successful procedure to be applied for predicting the transient interface in confined coastal aquifers.
\end{abstract}

Keywords: Confined coastal aquifer, analytical solution, prediction, transient interface

\section{Introduction}

In long-shore areas, where permeable materials extend to considerable depth, salt water will underlie fresh water according to Ghyben-Herzberg relation /1,2/ and will extend downward from the interface to the base of the impermeable material, Fig. (1).

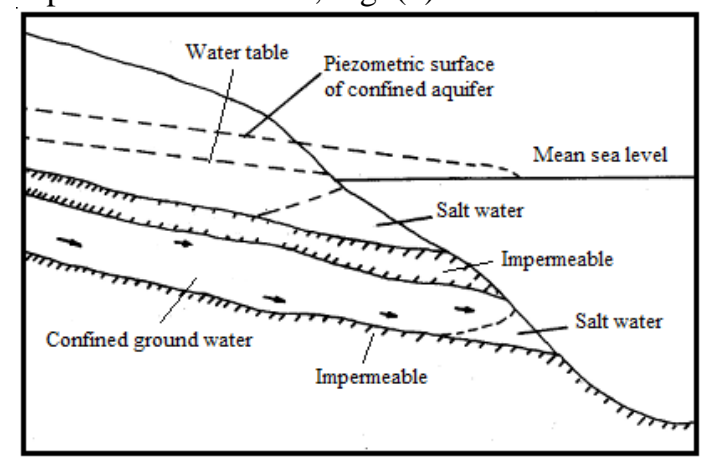

Figure 1: Diagrammatic section showing the relation of fresh ground water to salt water in coastal aquifer types.

The fresh-water body assumes the form of a lens floating on the top of the underlying sea water and is usually thickest at the central part of the land mass tapering to a thin edge at the shore margins, Fig. (1). The flow moves from the thickest part of the lens outward to the shore line and to other outlet margins. The magnitude of freshwater lens depends mainly on; the land mass width, permeability, recharge and discharge and tidal range $/ 3 /$.

\section{Background}

Many studies have been made concerning the groundwater flow in coastal aquifers. Simple but practical one-dimensional steady-state analytical models, /4,5)/ have been developed based on the GhybenHerzberg principle and the Dupuit's assumptions. Pinder and Cooper (1970), /6/, developed a numerical model for predicting the movement of the salt-water front in coastal aquifers.

More recently, for homogeneous and isotropic aquifers with straight boundaries, analytical solution can be used to estimate the steady location for the sharp interface, $17,8,9 /$. On the other hand, little is found about the problem of transient interface for confined coastal aquifers. A particular problem for variable interface was treated by Bear (1972) for horizontal confined aquifer whose theoretical considerations are given in /10/.In such aquifer discharging into the sea, where the piezometric surface is lowered, the interface will rise and salt water will move into the aquifer along its base above the impervious boundary. Actually, the motion of fresh groundwater to the discharge areas causes a reduction in flow to occur down gradient. However, the interface must adjust to conform with the new smaller flow rate. This is an unsteady flow problem and one must seek how much will be the advance of interface as will be studied beyond the scope here.

\section{Problem Formulation}

Consider a confined coastal aquifer bounded by straight impervious boundaries and is discharging into the sea. The formed fresh-salt water interface or simply interface separates the aquifer into two regions; one occupied by fresh water (fresh-water region) and the 
other occupied by sea water called (salt-water region), Fig. (2).

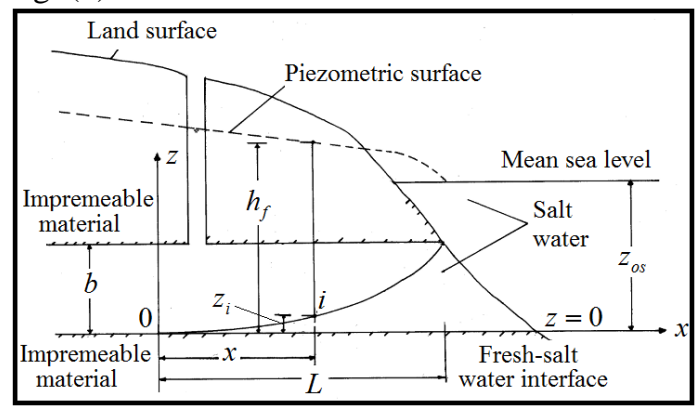

Figure 2: Definition sketch for flow in a confined aquifer discharging into the sea.

The Problem formulation will be achieved according to the following steps :

(1) The continuity equation applied on a control volume selected in the aquifer, Fig. (3) , gives the following equations :

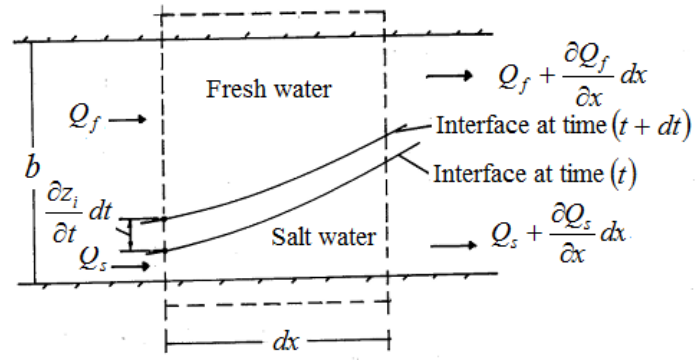

Figure

3: Details of unsteady flow in a control volume selected in a confined coastal aquifer.

For fresh-water region :

$\frac{\partial Q f}{\partial x}=n \frac{\partial z i s}{\partial t}$

For salt-water region :

$\frac{\partial Q s}{\partial x}=n \frac{\partial z i s}{\partial t}$

Where $Q_{f}$ and $Q_{s}$ are the flow rates per unit breadth of the aquifer for fresh and salt-water regions respectively, $\mathrm{n}=$ porosity of the aquifer, $z_{i s}=$ elevation of interface from origin at coordinate $\mathrm{x}$ and $\frac{\partial z i s}{\partial t}=$ time rate of change of location of interface.

(2) Using the Dupuit's assumption and Darcy's law, the flow rates in both regions are given by:

$$
\begin{aligned}
Q_{f} & =-K_{f} \frac{\partial h i f}{\partial x}(b-z i s) \\
\text { and } Q_{s} & =-K_{s} \frac{\partial z i s}{\partial x} z i s
\end{aligned}
$$

where $K_{f}$ and $K_{s}$ are the hydraulic conductivities of fresh and salt-water regions respectively, $\mathrm{b}=$ thickness of the confined aquifer, $\frac{\partial h i f}{\partial x}=$ slope of the piezometric surface and $\frac{\partial z i s}{\partial x}=$ slope of the interface

(3) Equal pressure ( pi ) at any point in the interface, Fig(2) yields : $p_{i}=w_{f}\left(h_{i f}-z_{i s}\right)=w_{s}\left(z_{o s}-z_{i s}\right)$

Where $w_{f}$ and $w_{s}$ are the specific weights of fresh and salt water respectively, $h_{i f}=$ depth of piezometric surface from the impermeable boundary and $z_{o s}=$ elevation of sea level from that boundary. Differentiating equation (5) with respect to $\mathrm{x}$ gives :

$\frac{\partial z i s}{\partial x}=-\left(\frac{w f}{w s-w f}\right) \frac{\partial h i f}{\partial x}$

That is to say; the slope of interface is $\left(\frac{W f}{w s-w f}\right)$ times the slope of the piezometric surface

(4) From equation (3) :

$$
\frac{\partial h i f}{\partial x}=-\frac{Q_{f}}{K f(b-z i s)}
$$

Correlation of equations (6) and (7) yields :

$$
\frac{\partial z i s}{\partial x}=\left(\frac{w f}{w s-w f}\right) \frac{Q f}{K f(b-z i s)}
$$

(5) Equations (1) and (2) show that at any vertical profile in the aquifer at coordinate $\mathrm{x}$ from the origin :

$Q_{f}+Q_{s}=\mathrm{f}(\mathrm{t})$. It is useful to define :

$Q_{o}=Q_{f}+Q_{s}$

Where $Q_{o}=$ the flow rate per unit breadth of the aquifer upstream at $\mathrm{x}=0, \operatorname{Fig}(2)$. From equation (9) at any coordinate $\mathrm{x}, Q_{f}=Q_{o}-Q_{s}$, substitution in equation (8) yields :

$Q_{o}-Q_{s}-\left(\frac{\mathrm{ws}-\mathrm{wf}}{\mathrm{wf}}\right) K_{f}(b-z i s) \frac{\partial z i s}{\partial x}=0$

Differentiate equation(10) with respect to $\mathrm{x}$ gives: $\frac{\partial Q 0}{\partial x}-\frac{\partial Q s}{\partial x}-\left(\frac{w s-w f}{w f}\right) K_{f}\left((\mathrm{~b}-\mathrm{z}\right.$ is $\left.) \frac{\partial 2 z i s}{\partial x}-\left(\frac{\partial z i s}{\partial x}\right)^{2}\right)=0$ (11)

Since $Q_{o}$ is independent of $\mathrm{x}$, then the term $\frac{\partial Q 0}{\partial x}$ can be eliminated from equation /10/. Also, from equation (2), $\frac{\partial Q s}{\partial x}=-n \frac{\partial z i s}{\partial t}$. Accordingly, equation (11) will take the form:

$\mathrm{n} \frac{\partial z i s}{\partial t}+\left(\frac{w s-w f}{w s}\right) K_{f}\left(\frac{\partial z i s}{\partial x}\right)^{2}-\left(\frac{w s-w f}{w f}\right) K_{f}(b-$ zis 2 zis $\partial x 2=0$ (12)

Correlation of equations (8) and (12) yields : $\mathrm{n} \frac{\partial z i s}{\partial t}+\left(\frac{w f}{w s-w f}\right) \frac{Q f 2}{(b-z i s)^{2}}-\left(\frac{w s-w f}{w f}\right) K_{f}(b-$ zis 2 zis $\partial x 2=0 \quad 13$

Equation (13) is a non-linear partial differential equation of the second order. A closed solution of this equation is not tried within the scope here, but the equation can be simply solved by neglecting the term $\left(\frac{\partial 2 z i s}{\partial x^{2}}\right)$ which represents the rate of change of the slope of interface with respect to $\mathrm{x}$, since in coastal confined aquifers the slope of interface is usually small and its derivative is of 
infinitesimal value ( about $2.8 \times(10)^{-7}$ within the scope here). Accordingly, equation (13) will have the following simpler form :

$$
\frac{\partial z i s}{\partial t}=-\left(\frac{w f}{w s-w f}\right) \frac{Q f 2}{n K f(b-z i s)^{2}}
$$

Physically, the minus sign in the right-hand side of equation (14), means that as the interface rises upward, $Q_{f}$ decreases. At any coordinate $\mathrm{x}$, zis is a function of $\mathrm{t}$ only and equation (14) can be written in total derivative instead of partial derivative. Integrating equation (14) between the limits at $\mathrm{t}=0, z_{i s}=L_{0}$ and at $\mathrm{t}=\mathrm{t}, z_{i s}=\mathrm{L}$, with $b=$ constant aquifer thickness, Fig(4), then :

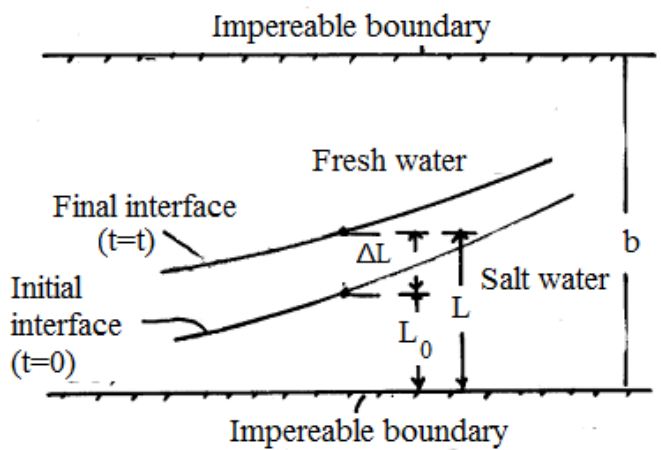

Figure 4: Sketch diagram showing subscripts denoting the advance of interface in a confined coastal aquifer.

$$
\int_{L 0}^{L}(b-z i s)^{2} d z i s=\left(\frac{w f}{w s-w f}\right) \frac{Q f 2}{n K f} \int_{0}^{t} d t \quad \text { which }
$$

reduces to

$$
\left.\Delta \mathrm{L}=\sqrt[3]{\left(3\left(\frac{w f}{w s-w f}\right)\right.} \frac{Q f 2}{n K f} t\right)
$$

Both sides of equation (15) have the dimensions of length and the parameter $(\Delta \mathrm{L})$ will represent the seasonal advance of interface after a time $\mathrm{t}$ at any distance $\mathrm{x}$ from the origin.

Derivation of equation (15) is based on the following assumptions:

(1) The aquifer is homogeneous and isotropic

(2) Two-dimensional potential flow in porous medium

(3) Quiet sharp interface between salt and fresh-water and the thickness of transition zone is ignored (4) The initial interface exists at the maximum levels of piezometric surface and is determined according to Ghyben-Herzberg

principle

(5) The rise of interface is mainly caused by the subsurface movement of groundwater to the underlying salt base where the interface adjusts to conform with new smaller flow rates

(6) The tidal effects are neglected.

\section{Application Example}

Table 1: Hydraulic properties of the underlying aquifers in the application example ,/11/
The developed equation is applied on the coastal artesian aquifer in central Suffolk County (Upton Area), Long Island, USA, Fig. (5), /11/

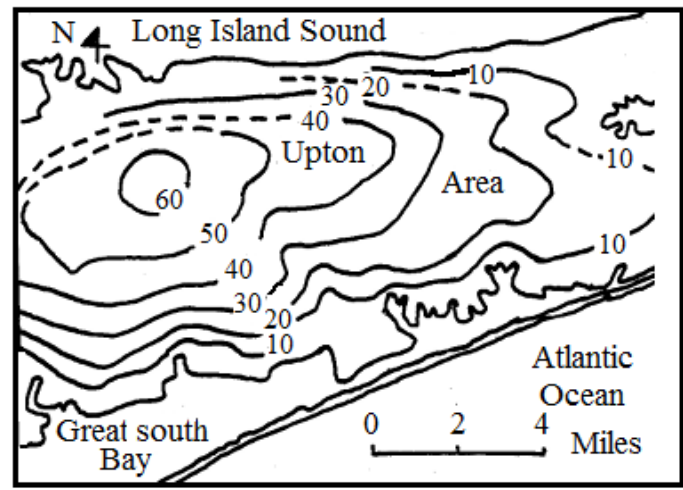

Figure 5: A generalized ground water level contour map of water bearing formations in the confined aquifer example Upton Area, USA (levels in ft) ,/11/

The purpose is to predict the movement of interface not in detail but with considerable confidence as to the average general pattern in the area. This is due to the lack of the precise data of groundwater levels near the shore line in the area.

In the study area, the aquifer system consists of; an upper aquifer, a semi-confining layer and the lower aquifer Fig. (6),/11/

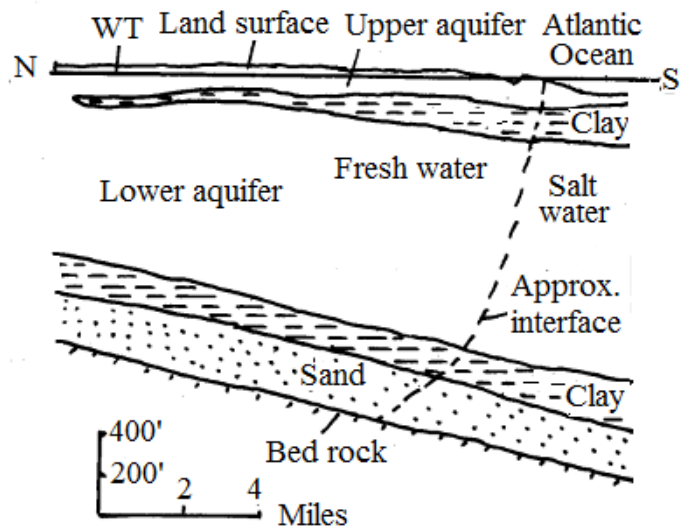

Figure 6: Schematic geologic cross section for the area of the aquifer example, /11/

The upper one consists of sand and gravel deposits and the semi-confining layer consists of clay which confines water in the upper aquifer. The lower aquifer is made of sandy clay and clayey sand of moderate to lower permeability at top, followed by a clay member of lower permeability below which there is a sand member composed of quartz pebbles, coarse to fine sand and silt and clay resting on a bed rock which acts as the impervious boundary of the lower aquifer, Fig. (6), /11/.

The hydraulic properties of the materials forming the aquifers are shown in Table (1). \begin{tabular}{|l|l|l|l}
\hline Aquifer & Transmissivity & Contrib. thickness & Hyd. Conduct.
\end{tabular} Porosity 


\begin{tabular}{|l|c|c|c|c|}
\hline & $\left(\mathrm{ft}^{2} / \mathrm{day}\right)$ & $(\mathrm{ft})$ & $(\mathrm{ft} / \mathrm{day})$ & \\
\hline Upper aquifer & 25400 & 145 & 175 & 0.33 \\
\hline $\begin{array}{l}\text { Lower aquifer-top } \\
\text { sandy clay }\end{array}$ & 5680 & 400 & 14.2 & 0.25 \\
\hline $\begin{array}{l}\text { Lower aquifer- } \\
\text { bottom sand }\end{array}$ & 1670 & 64 & 26 & 0.20 \\
\hline
\end{tabular}

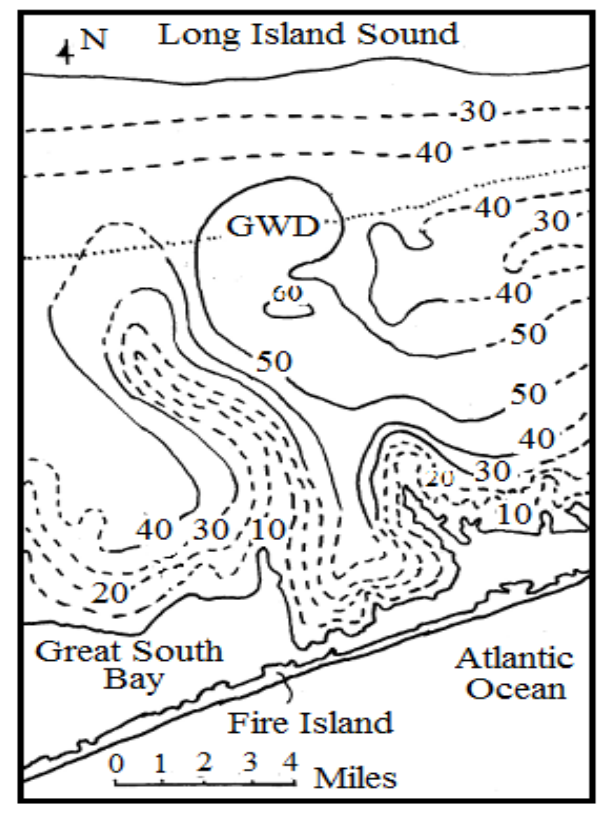

Figure 7: Contour map showing the generalized seasonal average change in ground water levels in area of study (levels in $\mathrm{ft}$ ), /11/

According to $/ 11 /$,correlation of groundwater levels measured for upper and lower aquifers shows that, the general pattern of groundwater movement is much the same. However, the upper and lower aquifers seem to be hydraulically connected through the semi-confining layer and the aquifer system may be considered as a confined leaky aquifer and is treated beyond the scope here as a single hydrologic unit.

In the area of study, a large part of precipitation percolates downward to the underlying aquifers, where fresh-groundwater floats on top of salt water in accordance with Ghyben-Herzberg principle and in areas near the shore, it is salted by sea water intruded in land. The groundwater levels are usually above sea level, /11/.Fresh-groundwater in the area usually discharges mainly into streams, pumped wells and naturally by subsurface outflow to the salt-water base. The groundwater level contour map, Fig. (5), shows that most of groundwater movement is southward toward the Atlantic ocean.

Long-term studies of fluctuations of groundwater levels indicate that, the groundwater surface attains its maximum levels in the spring and summer ( from about march to September) to low levels in winter (from about December to April). The intervals between the highest and lowest levels occurs from one on year to 7 months,/11/. On the average, the seasonal period of decline of ground water is 8 months. On the other hand, Fig. (7), shows the generalized average decline in groundwater between highest levels observed in July and lowest levels observed in February. These records are accepted to be representative for the area as present day average levels.

\section{Calculations and Results}

For the purpose of calculations, The elevations of piezometric surface above sea level and its seasonal decline are based on the mean values given in the maps of Figs. (5 and 7) respectively. The following data are given : $w_{s}$ (specific gravity of salt water) $=1.025, w_{f}$ (specific gravity of fresh water) $=1.0, \mathrm{n}$ (average porosity of the aquifer) $=0.27, K_{f}$ (average hydraulic conductivity of the aquifer system) $=\frac{175 \times 145+14.2 \times 400+26 \times 64}{145+400+64}=53.8 \mathrm{ft} /$ day $(16.4 \mathrm{~m} /$ day $)$, (Table(1) and/12/ and t (seasonal period of decline of piezometric surface $)=8$ months $(240$ day $)$

Investigation of Fig (5) shows that, the average hydraulic gradient measured from the groundwater divide to the shore line is 0.001 . Also, on the average, the elevation of piezometric surface above sea level is $20 \mathrm{ft}$ $(6.1 \mathrm{~m})$ ( considering the 0 -elevation coincides with the sea level). Then, according to Ghyben-Herzberg relation, $\mathrm{b}$ (average thickness of the aquifer) $=41 \times 20=820 \mathrm{ft}$ $(250 \mathrm{~m}) . Q_{f}$ (average flow rate of groundwater per unit breadth of the aquifer) $=53.8 \times 820 \times 0.001=44.116$ $\mathrm{ft} 3 /$ day (1.25 $\mathrm{m} 3 /$ day). Substitution of the previous parameters in the developed equation below,

$$
\left.\Delta \mathrm{L}=\sqrt[3]{3}\left(\frac{w f}{w s-w f}\right) \frac{Q f 2}{n K f} t\right)
$$

gives $\Delta \mathrm{L}$ (advance of interface $=156.8 \mathrm{ft}(47.8 \mathrm{~m})$. On the other hand, the map in Fig(7) shows that, the average seasonal decline of piezometric surface is $4 \mathrm{ft}(1.22 \mathrm{~m})$, then using the Ghyben-Herzberg relation, the corresponding $\Delta \mathrm{L}=160 \mathrm{ft}(48.78 \mathrm{~m})$.

\section{Conclusions}

Comparing the results for the seasonal average 
advance of interface $(\Delta \mathrm{L})$ in the studied coastal confined aquifer which are computed using the developed analytical solution and Ghyben-Herzberg relation, leads to the following conclusions :

(1)The compared average values of advance of interface $(\Delta \mathrm{L}) 156.8 \mathrm{ft}=47.8 \mathrm{~m}$ (developed equation) and $160 \mathrm{ft}$ $=48.78$ ( Ghyben-Herzberg relation), are found to have the same order of magnitude and of nearer values with little deviation of 0.02 .

(2) It is not necessary that the compared values should be exactly equal, because the equation is developed based on potential flow in porous medium, while GhybenHerzberg principle indicates a periodical static condition. (3)The agreement may be considered satisfactory where the analytical solution has the advantage of considering the hydraulic properties of the aquifer and the actual hydrological conditions existing in the studied area.

(4) It is advisable to apply the developed analytical solution for estimating the seasonal advance of interface on another confined coastal aquifer where the necessary sufficient precise detailed data are available in particular near the shore line

\section{Nomenclature}

$Q_{f}=$ flow rate per unit breadth of the aquifer in freshwater region

$Q_{s}=$ flow rate per unit breadth of the aquifer in saltwater region

$\mathrm{n}=$ porosity of the aquifer

$z_{i s}=$ elevation of interface from the lower boundary at coordinate $\mathrm{x}$

$\left(\frac{\partial z i s}{\partial t}\right)=$ time rate of change of elevation of interface

$\left(\frac{\partial h i f}{\partial x}\right)=$ slope of piezometric surface

$\left(\frac{\partial z i s}{\partial x}\right)=$ slope of the fresh-salt water interface

$K_{f}=$ hydraulic conductivity of the fresh-water region

$K_{s}=$ hydraulic conductivity of the salt-water region

$p_{i}=$ interface pressure at coordinate $\mathrm{x}$

$w_{f}=$ specific weight of fresh water

$w_{s}=$ specific weight of sea water

$\mathrm{b}=$ thickness of the confined aquifer

$Q_{o}=$ flow rate per unit breadth of the aquifer at the origin of coordinates

$\left(\frac{\partial 2 z i s}{\partial x^{2}}\right) \quad=$ rate of change of slope of interface with horizontal distance

$\Delta \mathrm{L}=$ seasonal advance of interface

\section{(7) References}

/1/ Badon Ghyben,w., 1889 : Notes on the probable of proposed well drilling near Amsterdam,Tydschrift Van het Koninkyhy Institute Van Ingenieurs. The Hague Netherlands, $21 \mathrm{pp}$.

12/ Herzberg, A., 1901 : The water supply on parts of the north sea coast, Journal Gasbeleucht, .U. Wasserver surg, Jahrg 44, Munich, Germany

13/ Urish, D.W.,1980 : Asymmetric variation of GhybenHerzberg lens, ASCE, Vol.106, No.Hy7, 1149-1158

14/ Fetter, C.W., 1972 : Saline water beach oceanic islands, Water Resources Research, Vol. 8, No. 5, 1307 1315

15/ Hennery, H.R., 1964 : Interfaces between salt water and fresh water in coastal aquifers, U.S. Geol. WaterSupply paper 1613-C,35-69

16/ Pinder, G.F., and Cooper, H.H., 1970 : A numerical technique for calculating the transient position of the salt-water front, Water Resources, Res. 6, 875-882/

17/ Bear, J., 1979 : Hydraulics of groundwater, McGraw Inc., $567 p p$

18/ Cheng, A.H., Haslhol, D., and Quazar, D., 2000 : Pumping optimization in saltwater-intruded_coastal aquifers, Water Resources, Res., Vol. 36, No. 8, 2155 21265

19/ Abdel Gawad, H.A., 2004 : Optimal utilization of unconfined aquifers, MEJ (Mansoura Eng. Journal), Faculty of Engineering, Mansoura University, Vol. 29, No. 2,C20-C32

/10/ Raudkivi, A.J., et al, 1976 : Analysis of groundwater flow, Edward Arnold (Publishers) Inc.,London, 171-182

111/ Warren, M.A., et al, 1968 : Hydrology of Brookhaven National Laboratory, Suffolk County, Long Island, New York, GSB (Geol. Survey Bulletin), 1156-C 112/Bouwer, H., 1978 : Hydrology, Mc-Graw Hill Inc, Series in Water resources and Environmental Engineering, New York, 57-58

\section{Author's Information}

1 Professor of Hydraulics in the Department of Civil Eng. , Faculty of Eng., Port-Said University. The Author is very interesting in the fields of, Groundwater Hydrology, Hydraulic Engineering and Applied fluid Mechanics . The author has many publications in these fields (38 papers) 